\title{
ANALISIS PEMANFAATAN DUA ELEMEN PELTIER PADA PENGONTROLAN TEMPERATUR AIR
}

\author{
Meqorry Yusfi ${ }^{1, \text { a) }}$, Frima Gandi, Heru Sagito Palka \\ ${ }^{1}$ Jurusan Fisika FMIPA Universitas Andalas Kampus limau manis Padang 25163 \\ Email: ${ }^{\text {a) }}$ meqorry@yahoo.com
}

\begin{abstract}
Abstrak
Elemen peltier bisa digunakan sebagai pemanas dan pendingin. Pada penelitian ini elemen peltier digunakan sebagai pendingin air. Tujuan dari penelitian ini adalah untuk membandingkan hasil pemakaian antara satu dan dua elemen peltier pada sistem kontrol temperatur air. Alat dirancang dengan menggunakan LM35 sebagai sensor temperatur dan mikrokontroler Atmega 8535 untuk mengontrol sebelum ditampilkan ke LCD. Sistem kontrol On-off digunakan pada sistem ini. Hasil penelitian menunjukkan bahwa kemampuan dari elemen peltier menurun seiring meningkatnya massa air. Kemampuan elemen pertier dalam melakukan proses pendinginan bergantung pada jenis transfer panasnya, walaupun dengan menggunakan satu elemen peltier, transfer panas dengan memanfaatkan heatsink dan fan lebih baik daripada menggunakan pompa menggunakan dua elemen peltier. Dua elemen peltier memiliki kemampuan menurunkan temperatur lebih cepat dimenit-menit awal, namun untuk mencapai keadaan set temperatur, satu elemen lebih cepat daripada dua elemen peltier untuk rangkaian yang berbeda. Cara transfer panas dari elemen peltier juga mempunyai pengaruh yang cukup besar pada kemampuan pendinginan air untuk mencapai temperatur minimum.
\end{abstract}

KataKunci: elemen peltier, sistem kontrol, temperatur air, pendingin

\begin{abstract}
Peltier element can be used as a heating or cooling in a system. In this research the peltier element is used as a cooler in water.The research purpose is to compare the result between one and two element peltier in water temperature control system. The prototype is designed using LM35 as temperature sensor and Atmega8535 microcontroller to process the output of the sensor before displayed on LCD. On-off control is used to control the system. The results show the ability of a Peltier element decreases with the increasing of the mass of water. The ability of peltier element in cooling system depent on heat transfer, eventough using one element, heat transfer using heat sink dan fan is better than using pump with two peltier element. Two element decreasing the temperatur faster than one in early cooling, but slower to reach setting temperature bu using this circuit. The way to transfer heat from peltier element also have significant effect to get minimum cooling temperature.
\end{abstract}

Keywords: peltier element, control system, water temperature, cooling 


\section{PENDAHULUAN}

Elemen Peltier adalah komponen termoelektrik yang dapat memompa panas dari satu sisi ke sisi lain sesuai arah arus yang diberikan. Prinsip kerja elemen Peltier berdasarkan efek Peltier, Joule, Seebeck, dan Thomson [1]. Ketika arus DC dialirkan ke elemen Peltier, akan mengakibatkan salah satu sisi elemen Peltier menjadi dingin (kalor diserap) dan sisi lainnya menjadi panas (kalor dilepaskan). Elemen Pertier dapat dimanfaatkan sebagai pemanas dan pendingin bergantung pada arah arus yang diberikan.

Elemen Peltier berwujud padat, terdiri dari bahan semikonduktor tipis dilapisi konduktor serta keramik dibagian luarnya [2]. Elektron mengalir dari tingkat energi lebih tinggi ke tingkat energi lebih rendah. Elektron dari material yang kekurangan elektron (P-type material) bergerak ke material yang kelebihan elektron (N-type material). Dalam keadaan ini maka konektor akan menyerap energi sehingga sisi ini akan menjadi sisi dingin dari peltier. Di lain pihak, ketika elektron bergerak dari $N$-type menuju P-type, maka konektor akan melepas energi sehingga sisi ini akan menjadi sisi panas dari peltier. Perbedaan temperatur inilah yang akan menghasilkan beda tegangan.

Transfer panas dari elemen peltier dapat dilakukan dengan beberapa cara seperti dengan menggunakan kipas dan heatsink, pipa dan kipas, dll. Kemampuan dari sistem pendingin bergantung pada perbedaan temperatur dari kedua sisi elemen, bentuk geometri dan disipasi panas alami [3].

Pemanfaatan elemen peltier banyak diaplikasikan dalam sistem kontrol temperatur, terutama pada proses pendinginan seperti untuk sistem kontrol temperatur udara [4] dan temperatur air [5]. Pada penelitian ini sistem kontrol yang dipakai adalah sistem kontrol on-off. Sistem kontrol ini dipakai karena sederhana dan tidak memerlukan pemrograman yang kompleks, sehingga dapat diaplikasikan dengan mudah.

\section{METODE PENELITIAN}

Penelitian ini akan membandingkan pemakaian satu dan dua elemen peltier. Pemasangan satu elemen peltier akan menggunakan heatsink dan pompa sebagai alat transfer panas.

\subsection{Perancangan Sistem Pendingin Menggunakan 1 Elemen Perltier}

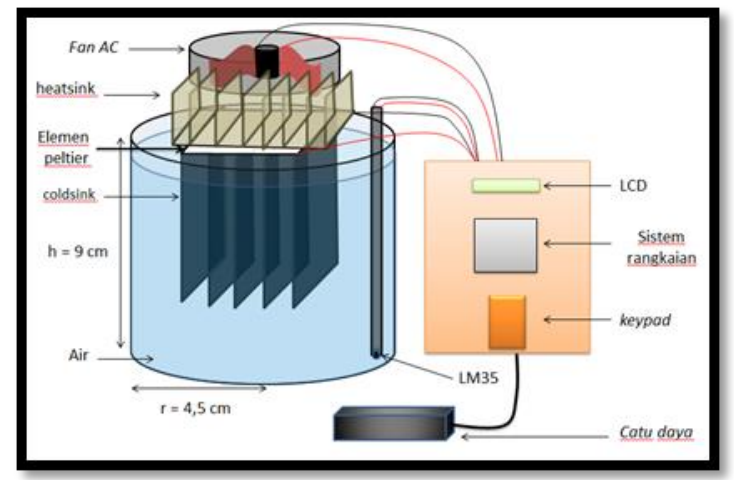

Gambar 1. Sistem kontrol temperatur air dengan menggunakan 1 elemen peltier [5]

Sistem kontrol temperatur air dengan menggunakan satu elemen peltier dapat dilihat pada Gambar 1. Kipas (Fan AC), heatsink dan coldsink dipakai untuk mengoptimalkan transfer panas dari elemen peltier ke air.

Proses pengontrolan diawali dengan masukan pada keypad. Ketika sistem rangkaian dihidupkan, LM35 mendeteksi temperatur air sebagai temperatur awal. Temperatur yang diinginkan dimasukkan lewat keypad. Sinyal dari keypad akan diproses oleh mikrokontroler. Jika terdapat sinyal error (selisih antara sinyal terbaca dengan sinyal masukan), maka relai akan aktif. Jika relai aktif, maka elemen Peltier dan fan AC hidup.

Elemen Peltier akan memompa panas yang ada di dalam air ke luar. Sisi bagian bawah elemen Peltier akan menyerap panas lewat heatsink. Panas yang diserap akan dilepaskan pada bagian sisi atas yang akan diserap lagi oleh heatsink. Fan AC membantu untuk mempercepat pembuangan panas 
ke udara. Proses ini terjadi sampai temperatur yang terbaca sama dengan temperatur yang dimasukkan. Setelah syarat ini terpenuhi, elemen Peltier akan mati dan berhenti menyerap panas.

\subsection{Perancangan Sistem Pendingin Menggunakan 2 Elemen Perltier}

Perancangan sistem pendingin dengan 2 elemen peltier memanfaatkan pompa untuk mengoptimalkan transer panas. Elemen peltier dipasang dengan dua cara yaitu secara serie dan paralel.

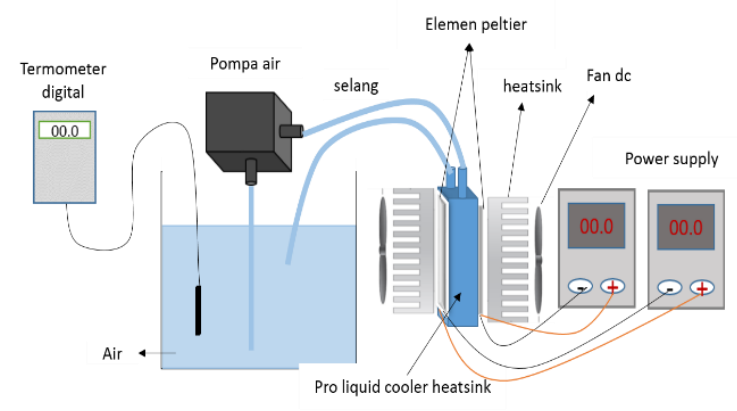

Gambar 2. Sistem kontrol temperatur air dengan menggunakan 2 elemen peltier.

Dua buah elemen Peltier terpasang pada kedua sisi logam aluminium ( pro liquid cooler heatsink ) seperti ditunjukkan oleh Gambar 2. Logam ini berfungsi sebagai pengonduksi elemen Peltier ke air yang dipompakan dari box ke logam aluminium. Pada saat proses pendinginan, sisi panas elemen Peltier juga dilengkapi dengan fan DC untuk mempercepat pembuangan panas ke lingkungan. Dengan cara ini diharapkan proses pendiginan cepat terjadi dan bisa mencapai temperatur minimum dengan beban maksimal. Pada saat proses pemanasan, maka fan DC tidak dihidupkan karena sisi elemen Peltier yang didekat fan adalah sisi dingin.

Sensor LM35 diletakkan di dasar tabung agar temperatur air yang jauh dari selang pompa bisa dideteksi. Keypad, LCD dan sistem rangkaian diletakkan pada satu tempat. Hal ini bertujuan agar mudah dalam mengoperasikan sistem pengontrolan.

Percobaan dibagi menjadi dua bagian yaitu dengan menghubungkan elemen peltier secara serie dan secara paralel dengan catu daya. Sedangkan sistem kontrol yang dipakai adalah sistem kontrol on-off dengan setting temperatur $15^{\circ} \mathrm{C}$.

\section{HASIL DAN PEMBAHASAN}

\subsection{Pengujian Kemampuan Satu Elemen Peltier dalam Melakukan Pendinginan}

Sistem pendingin menggunakan satu elemen peltier dipasang menggunakan kipas dan heatsink untuk transfer panas dengan rangkaian seperti pada Gambar 1. Catu daya yang diberikan adalah 12 V/3 A, hasil yang diperoleh seperti terlihat pada Gambar 3.

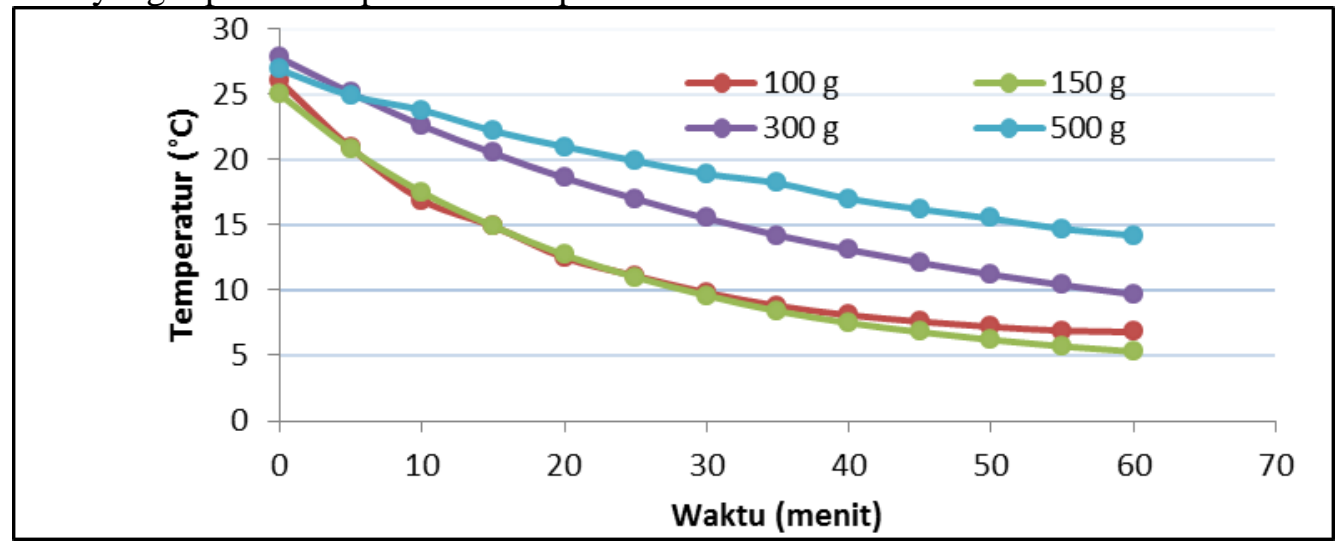

Gambar 3. Grafik hubungan temperatur terhadap waktu pada proses pendinginan menggunakan satu elemen Peltier 
Kemampuan pendingin berkurang dengan bertambahnya massa beban. Namun pada beban yang bermassa $150 \mathrm{~g}$ terlihat kurvanya hampir sama dengan kurva pada beban bermassa $100 \mathrm{~g}$ seperti terlihat pada Gambar 3. Temperatur minimum yang dapat dicapai beban $150 \mathrm{~g}$ dalam waktu 60 menit bahkan lebih rendah dibanding beban bermassa $100 \mathrm{~g}$. Pengecualian ini terjadi dikarenakan oleh temperatur awal yang berbeda. Temperatur awal beban $150 \mathrm{~g}$ lebih rendah dibandingkan temperatur awal beban $100 \mathrm{~g}$ sehingga kemampuan pendingin lebih baik pada beban $150 \mathrm{~g}$. Dapat disimpulkan bahwa temperatur ruangan mempengaruhi kemampuan pendingin dalam mendinginkan beban.

\subsection{Pengujian Kemampuan Dua Elemen Peltier dalam Melakukan Pendinginan}

Berdasarkan grafik pada Gambar 4, diperoleh hasil bahwa kemampuan proses pendinginan air oleh dua elemen Peltier yang dihubung secara serie (b) tidak jauh berbeda dengan dua elemen Peltier yang dihubung secara paralel (a). Secara teori kemampuan dalam mendinginkan air oleh dua elemen Peltier yang dihubung seri lebih baik daripada dua elemen Peltier yang dihubung secara paralel. Hal ini dikarenakan elemen Peltier yang dihubung secara seri tidak akan menerima arus yang terbagi melainkan arus yang maksimal, sehingga kemampuan elemen Peltier dalam mendinginkan air juga akan maksimal.

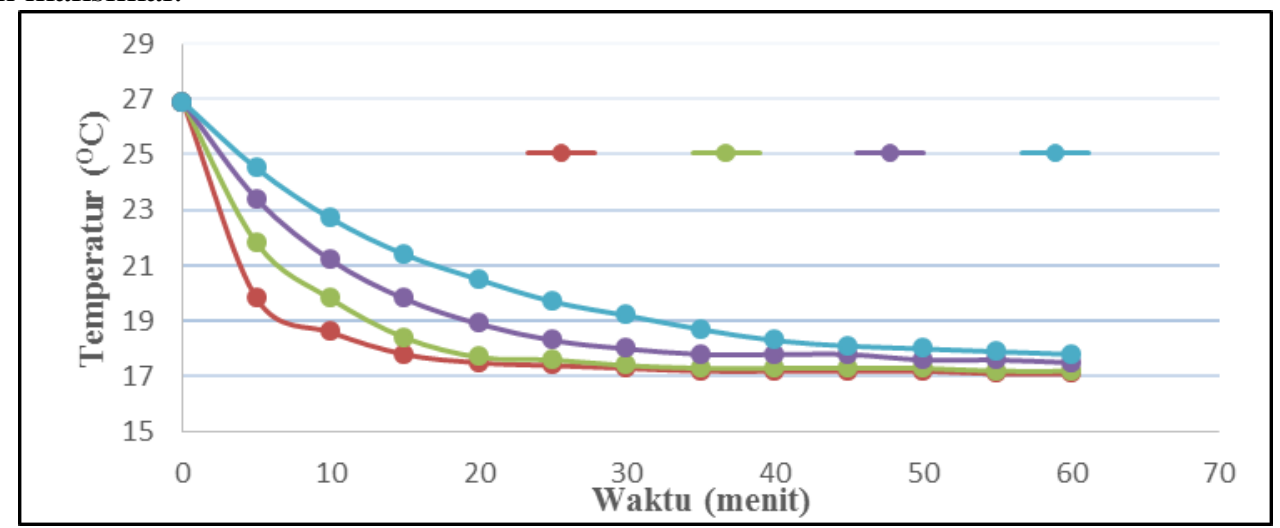

(a)

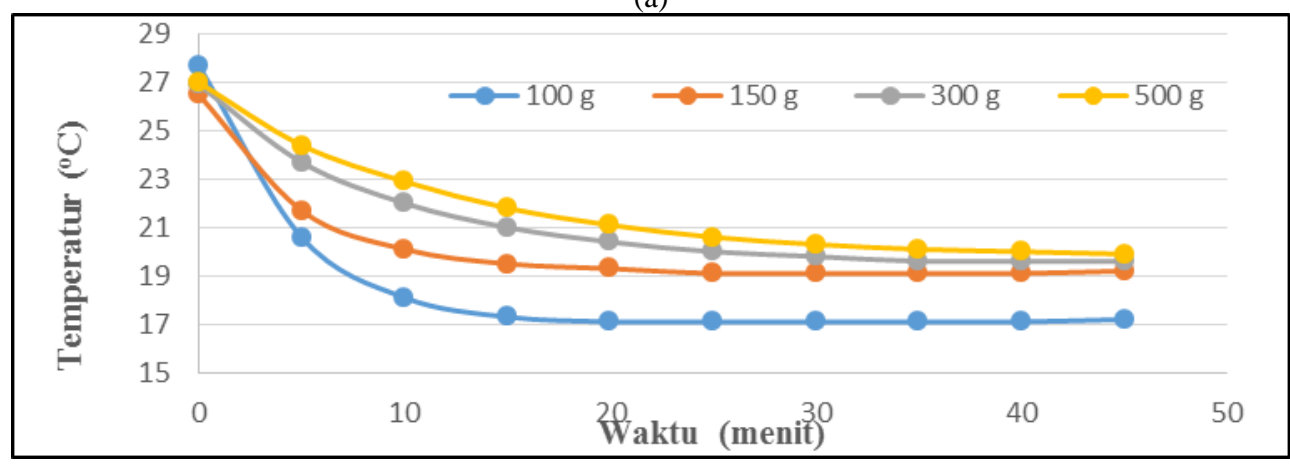

(b)

Gambar 4. Grafik hubungan temperatur terhadap waktu pada proses pendinginan menggunakan dua elemen Peltier yang dihubung secara (a) paralel dan (b) serie pada tegangan 12V/3A untuk beberapa massa air

Dua elemen Peltier dapat menurunkan temperatur air bermassa $100 \mathrm{~g}$ menjadi $17,2^{\circ} \mathrm{C}$ selama 45 menit. Nilai temperatur tersebut sama dengan nilai temperatur yang dicapai oleh dua elemen Peltier yang dihubung secara paralel pada massa $100 \mathrm{~g}$., namun pada proses pendinginan air bermassa $100 \mathrm{~g}$ dan 150 g terjadi kenaikan temperatur air pada menit 45 . Hal ini terjadi karena kemampuan elemen Peltier dalam melakukan proses pendinginan menurun akibat pengaruh sisi panas elemen Peltier. Semakin besar waktu maka sisi panas elemen Peltier akan semakin panas dan sisi dingin elemen Peltier akan semakin dingin. Sisi panas elemen Peltier dapat mempengaruhi sisi dingin elemen Peltier 
karena heatsink dan fan dc pada sisi panas berukuran kecil sehingga tidak maksimal dalam memompa kalor pada sisi panas elemen Peltier, serta heatsink yang digunakan berongga sehingga kalor pada sisi panas elemen Peltier tidak dapat mengalir secara maksimal ke heatsink.

Temperatur minimum yang dicapai oleh satu elemen pertier yang menggunakan kipas dan heatsink lebih rendah $\left(5,7^{\circ} \mathrm{C}\right)$ jika dibandingkan dengan dua elemen peltier yang menggunakan pompa, heatsink dan fan ac $\left(19,3{ }^{\circ} \mathrm{C}\right)$ dalam waktu 60 menit. Dilihat dari proses penurunan temperatur pada awal pendinginan, penggunakaan pompa menghasilkan penurunan yang lebih tajam di menitmenit awal dibandingkan tanpa pompa. Dapat disimpulkan, bahwa untuk proses penurunan temperatur yang cepat dapat menggunakan pompa, namun tidak bisa dipakai untuk temperatur yang sangat rendah dari temperatur ruang.

\subsection{Pengujian Sistem Kontrol Pendinginan Air}

Setelah mengetahui kemampuan dari pendingin menggunakan elemen peltier, maka dirancang suatu sistem kontrol pendinginan. Sistem kontrol yang dipakai adalah sistem kontrol on-off dengan setting temperatur $15^{\circ} \mathrm{C}$.

Hasil pada pengujian sistem kontrol dengan set temperatur $15^{\circ} \mathrm{C}$ untuk satu elemen peltier dapat dilihat pada Gambar 5. Dari grafik terlihat waktu yang dibutuhkan untuk mencapai temperatur acuan cukup lama. Akibatnya kecepatan pendinginan untuk menuju temperatur acuan menurun yaitu $0,0026^{\circ} \mathrm{C} / \mathrm{s}$. Perbedaan ini terjadi karena temperatur awal air yang tinggi dan set temperatur yang rendah sehingga pendingin membutuhkan waktu lama untuk mencapai temperatur acuan. Selain itu, waktu yang dibutuhkan untuk naik dari keadaan di bawah temperatur acuan lebih singkat dibandingkan waktu yang dibutuhkan untuk turun ketika berada di atas temperatur acuan. Begitu juga ketika temperatur air berada pada posisi temperatur acuan, temperaturnya lebih singkat ketika dalam posisi naik dibandingkan ketika dalam posisi turun. Perbedaan ini terjadi karena temperatur ruangan yang berbeda. Jika temperatur ruangan tinggi, maka waktu yang dibutuhkan untuk mempertahankan temperatur ketika sistem kontrol mati lebih singkat. Sebaliknya ketika sistem kontrol sedang hidup pada posisi turun, temperatur akan tertahan lebih lama hingga sampai menurunkan $0.5^{\circ} \mathrm{C}$.

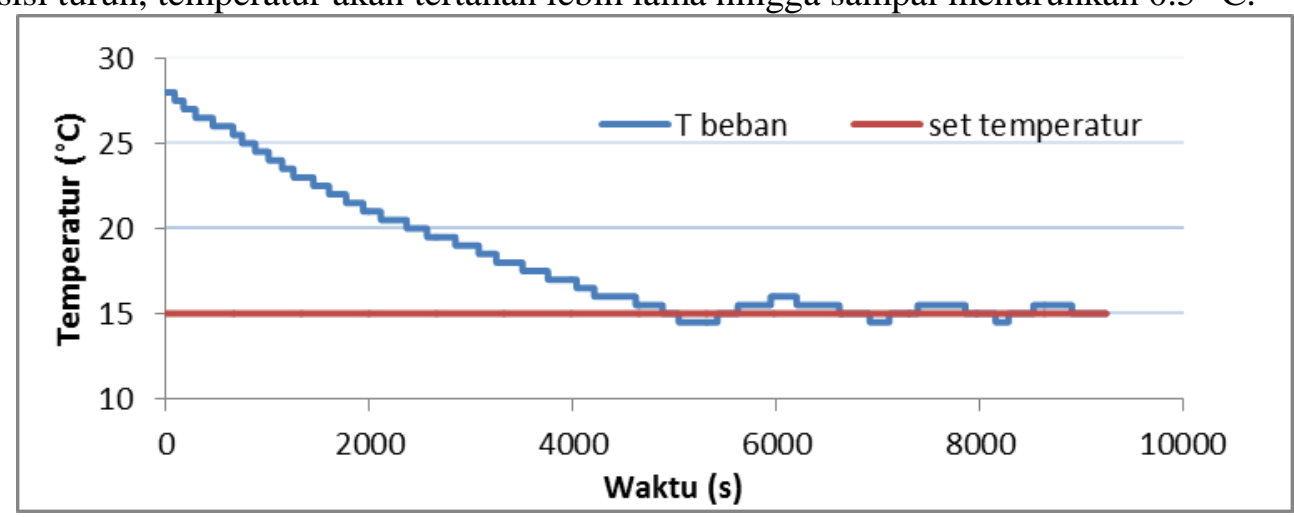

Gambar 5 Grafik pengujian kontrol temperatur menggunakan satu elemen peltier dengan set temperatur $15^{\circ} \mathrm{C}$

Pengujian sistem kontrol menggunakan dua elemen peltier dilakukan untuk set temperatur $17{ }^{\circ} \mathrm{C}$ karena berdasarkan hasil sebelumnya dalam waktu 60 menit kemampuan elemen tidak mencapai temperatur $15{ }^{\circ} \mathrm{C}$. Gambar 6 memperlihatkan proses pendinginan air dimulai pada temperatur awal sebesar $27,3{ }^{\circ} \mathrm{C}$ saat detik ke-0 sampai temperatur acuan sebesar $17{ }^{\circ} \mathrm{C}$ pada detik ke-4491. Sistem ini dapat mengontrol temperatur yang berkisar pada nilai acuan yang diinputkan. Sistem kontrol akan mematikan proses pendinginan saat temperatur air sedikit lebih kecil dari nilai temperatur acuan yaitu sebesar $16,6{ }^{\circ} \mathrm{C}$. Setelah itu temperatur air naik karena pengaruh lingkungan sampai $17,1^{\circ} \mathrm{C}$. Saat itu sistem kontrol kembali mengaktifkan sistem pendinginan sampai nilai temperatur terbaca $16,6{ }^{\circ} \mathrm{C}$ dan begitu seterusnya. 


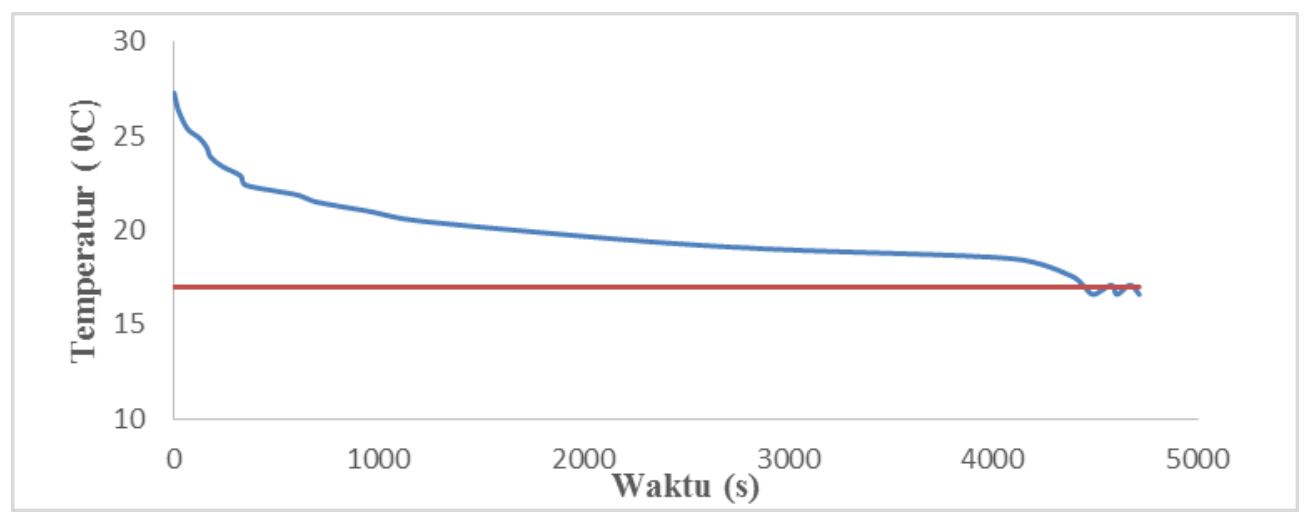

Gambar 6 Grafik pengujian kontrol temperatur pada proses pendinginan air menggunakan dua elemen peltier dengan set temperatur $17^{\circ} \mathrm{C}$

Jika dibandingkan kemampuan sistem kontrol dari satu elemen dan dua elemen, maka dihasilkan bahwa dua elemen memiliki kemampuan menurunkan temperatur lebih cepat dimenit-menit awal, namun untuk mencapai keadaan set temperatur, satu elemen lebih cepat daripada dua elemen.

\section{SIMPULAN}

Berdasarkan pengujian dan analisis yang telah dilakukan maka diperoleh kesimpulan:

1. Kemampuan elemen pertier dalam melakukan proses pendinginan bergantung pada jenis transfer panasnya, walaupun dengan menggunakan satu elemen peltier, transfer panas dengan memanfaatkan heatsink dan fan lebih baik daripada menggunakan pompa menggunakan dua elemen peltier.

2. Sistem kontrol dengan dengan menggunakan fan dan heatsink menghasilkan set temperatur yang lebih rendah dibandinkan dengan pompa.

3. Dua elemen memiliki kemampuan menurunkan temperatur lebih cepat dimenit-menit awal, namun untuk mencapai keadaan set temperatur, satu elemen lebih cepat daripada dua elemen peltier untuk rangkaian yang berbeda.

\section{UCAPAN TERIMAKASIH}

Peneliti mengucapkan terimakasih kepada DIPA Universitas Andalas yang telah membiayai penelitian ini dengan surat perjanjian pelaksanaan penelitian nomor : 01/UN.16/DM/LPPM/I/2015.

\section{DAFTAR PUSTAKA}

[1] Astrain, David, and Álvaro Martínez (2012). Heat Exchangers for Thermoelectric Devices, Heat Exchangers- Basics Design Applications, Dr. Jovan Mitrovic (Ed.), InTech, DOI: 10.5772/33464. Available from: http://www.intechopen.com/books/heat-exchangers-basicsdesign-application/heat-exchangers-for-thermoelectric-devices

[2] Gabert, Anders. Temperature Stabilization of Electronics Module. Master's Thesis. Dept. Of Computer Science and Electrical Engineering Lulea University of Technology (2006).

[3] Roj, Robin , Nils Katenbrink. Investigation on the Application of Different Air-CoolingSystems in a Thermoelectric Setup. Materials Today: Proceedings 2 ( 2015 )p. $714-720$.

[4] Y. Meqorry, P. Wilka, Derisma. Rancang Bangun Sistem Kontrol Temperatur untuk Proses Pendinginan Menggunakan Termoelektrik. Prosiding bidang Fisika Semirata 2015 Bidang MIPA BKS-PTN Barat Universitas Tanjungpura Pontianak (2015), p. 194-203

[5] Gandhi, Frima dan Yusfi, Meqorry. Perancangan Sistem Pendingin Air Menggunakan Elemen Peltier Berbasis Mikrokontroler ATmega8535, Jurnal Fisika Unand Vol. 5, No. 1 (2016), p.35-41 